\title{
Diversidade genética de cepas do fungo Arthrobotrys spp. predador de nematóides por RAPD e PCR-RFLP do rDNA*
}

\author{
Genetic diversity of nematode predacious fungi Arthrobotrys spp. by \\ RAPD and rDNA PCR-RFLP
}

Jackson Victor de Araújo, ** Moema Lopes Ramos, Elza Fernandes Araújo, Fabrícia Hallack Loures e Paulo Henrique Alves**

\begin{abstract}
Resumo
A diversidade genética de seis cepas de Arthrobotrys conoides, três de $A$. oligospora e sete de $A$. robusta foi avaliada por meio de RAPD. A amplificação resultou em um total de 107 fragmentos de DNA polimórficos, utilizando-se 11 oligonucleotídeos. As distâncias genéticas variaram de 9 a $83 \%$, quando analisadas em conjunto, demonstrando grande diversidade genética das cepas dessas três espécies. Por meio dessas análises, pôde-se diferenciar as cepas A51 (A.robusta) e A78 (A.conoides) das suas respectivas espécies. Além desses, a cepa A183 (A.oligospora) também se diferenciou de sua espécie agrupando-se com cepas de A. robusta. A variação dentro do espaçador interno transcrito (ITS) do rDNA de seis cepas de A.conoides e sete de A.robusta foi analisada por PCR seguida pela análise de "restriction fragment length polimorphism" (RFLP). Duas cepas fúngicas, A51 e A78, apresentaram polimorfismo de tamanho de fragmentos dentro de suas respectivas espécies. Os produtos da amplificação da região ITS foram hidrolisados com diferentes endonucleases de restrição. Análises de agrupamento, baseadas nos fragmentos de DNA de restrição, separaram as cepas em três distintos grupos: o Grupo 1, que contém aquelas pertencentes à espécie A.conoides, exceto a cepa A78; O Grupo 2, que contém as cepas da espécie A.robusta, exceto a A51; e o Grupo 3, formado pelas cepas A78 e A51, sugerindo uma nova análise na sua classificação.
\end{abstract}

Palavras-chave: fungos nematófagos, Arthrobotrys, RAPD, PCR-RFLP, rDNA, marcadores moleculares.

\section{Abstract}

The genetic diversity of six strains of Arthrobotrys conoides, three of A. oligospora, and seven of $A$. robusta was evaluated by RAPD. Total DNA amplification using 11 oligonucleotides resulted in 107 distinct polymorphic DNA fragments. The genetic distances varied from 9 to $38 \%$, showing high genetic diversity among the isolates of the three species. By means of RAPD analysis, the strain $A 51$ ( $A$. robusta) and A78 (A. conoides) could be differentiated from their respective species. Besides $A 51$ and $A 78$, the strain $A 183$ ( $A$. oligospora) also differentiated from its species, grouping with the strains of $A$. robusta. Variation within the rDNA ITS region of six strains of $A$. robusta was analyzed by PCR, followed by restriction fragment length polymorphism analysis (RFLP). The amplified region included the internal transcribed spacer (ITS), wich possesses a low degree of conservation. Two fungal strains presented length polymorphism within their respective species. Amplification products of the ITS region were cleaved with different restriction endonucleases. Cluster analysis based on restriction fragments divided the strains into three groups: Group 1, containing the A. conoides isolates, except A78; Group 2, containing the A. robusta strains, except A51; and Group 3 , formed by $A 78$ and $A 51$, suggesting that their classification should be revised.

Keywords: nematophagous fungi, Arthrobotrys, RAPD, PCR-RFLP, rDNA, molecular markers.

\section{Introdução}

Existem aproximadamente 200 espécies de fungos que pertencem à classe Deuteromycetes e são nematófagos. Nordbring-hertz (1988) afirmou que fungos nematófagos vêm atraindo a atenção dos pesquisadores desde que a sua função como predadores de nematóides foi reconhecida. Isto ocorre, em grande parte, por causa da captura drástica de nematóides, que pode ser facilmente demonstrada quando uma placa de Petri, com espalhamento de solo de origem apropriada, é observada sob microscópio estereoscópico.
Segundo Araújo (1999), dentre as pesquisas alternativas empregadas no controle biológico das helmintoses de animais domésticos, os fungos nematófagos apresentam-se como uma das mais promissoras, sendo que esses fungos reduzem efetivamente os estágios pré-parasitários de nematóides em laboratório e no meio ambiente. De acordo com Van Oorschot (1985), o gênero Arthrobotrys apresenta 27 espécies e pertence ao grupo de fungos predadores. Eles são classificados com base na dimensão e no formato dos conídios e conidióforos, nas ramificações e/ou na proliferação dos conidióforos e nos tipos de órgãos de captura (arma-

\footnotetext{
* Projeto financiado pela FAPEMIG.

** Bolsistas do CNPq.

Departamento de Veterinária, Universidade Federal de Viçosa, CEP 36571-000, Viçosa-MG, Brazil, Phone: 55 0XX 3138991464 ,

Fax: 55 0XX 31 38992317, E-mail: jvictor@mail.ufv.br
} 
dilhas). Espécies desse gênero são facilmente cultivadas em meios artificiais, e numerosas cepas são mantidas em diversos laboratórios do mundo. A identificação de Arthrobotrys spp segue, atualmente, as chaves de Cooke e Godfrey (1964), Haard (1968) e Van Oorschot (1985). A classificação de fungos predadores, com base em caracteres morfológicos, às vezes, exige uma decisão subjetiva do especialista. O formato e a cor do micélio, dentre outras, que não têm limites bem definidos, requerem experiência e alta capacidade de discernimento, principalmente, quando se tem em mãos uma cepa que não se enquadra no padrão típico da espécie. Além disso, a dimensão dos conídios e a ramificação dos conidióforos, dentre outras, podem sofrer variações de acordo com as condições de cultivo, tornando-se, muitas vezes, características insuficientes para uma identificação precisa de espécies taxonomicamente próximas (Cooke e Godfrey, 1964). Por causa dessas dificuldades, certos pesquisadores vêm empregando métodos alternativos, tais como análise de proteínas e de isoenzimas e dos marcadores de DNA RFLP ("Restriction Fragment Length Polimorphism"), ou polimorfismo de comprimento dos fragmentos de restrição; RAPD ("Random Amplified Polymorphic DNA") ou polimorfismo de DNA amplificado ao acaso para dirimir dúvidas e validar o uso de caracteres morfológicos (Araújo et al., 1997). O objetivo deste trabalho foi avaliar a diversidade genética entre cepas do gênero Arthrobotrys por meio da utilização de RAPD e PCR-RFLP da região ITS ("internal transcribed spacer") ou espaçador interno transcrito do rDNA.

\section{Material e métodos}

Foram analisadas por RAPD 16 cepas de Arthrobotrys spp oriundas de solo do Brasil (Tabela 1), sendo seis de A.conoides, três de A.oligospora e sete de A.robusta. Outras seis cepas de A.conoides e sete de A.robusta foram submetidas ao PCR-RFLP do rDNA.

Tabela 1 - Espécies de Arthrobotrys, origem, ano de isolamento e detecção em amostras de solo de diferentes culturas

\begin{tabular}{llll}
\hline \multicolumn{1}{c}{ Espécies } & Cepa & \multicolumn{1}{c}{ Origem/ano } & \multicolumn{1}{c}{ Cultura vegetal } \\
\hline A. conoides & A 32 & Jaguapitã/SP (1990) & Não determinada \\
A. conoides & A 40 & Jaguapitã/SP (1990) & Não determinada \\
A. conoides & A 74 & Dourados/MS (1991) & Milho \\
A. conoides & A 78 & V. do Rio Branco/MG (1990) & Arroz \\
A. conoides & A 241 & Papanduva/SC (1993) & Alho \\
A. conoides & A 266 & Curitibanos/SC (1993) & Alho \\
A. oligospora & A 72 & Dourados/MS (1991) & Soja \\
A. oligospora & A 125 & Rondonópoles/MT (1991) & Seringueira \\
A. oligospora & A 183 & Cajuri/MG (1992) & Citrus \\
A. robusta & A 31 & Jaguapitã/SP (1990) & Não determinada \\
A. robusta & A 35 & Atalaia/PR (1990) & Não determinada \\
A. robusta & A 38 & Viçosa/MG (1990) & Milho \\
A. robusta & A 51 & Matipó/MG (1991) & Feijão \\
A. robusta & A 75 & Dourados/MS (1991) & Café \\
A. robusta & A 134 & Ipeúma/SP (1992) & Milho \\
A. robusta & A 265 & Flores da Cunha/RS (1993) & Alho \\
\hline
\end{tabular}

As culturas-estoque das cepas de Arthrobotrys spp foram cultivadas por sete dias em meio batata-dextrose-ágar $2 \%$ (BDA), a $25^{\circ} \mathrm{C}$. Discos de cultura foram repicados para placas de Petri, contendo $20 \mathrm{~mL}$ de meio de cultura BDA. Nessas placas, os fungos cresceram por sete dias, a $25^{\circ} \mathrm{C}$ e no escuro. Posteriormente, esses discos, contendo micélio, foram removidos da periferia da cultura e colocados e cultivados no meio líquido de Kado e Hesket (1970) por sete dias a $25^{\circ} \mathrm{C}$. A extração do DNA total dos micélios foi feita em pequena escala, conforme Spech et al. (1982). Para a análise em RAPD, as reações da amplificação do DNA total foram feitas utilizandose 11 oligonucleotídeos aleatórios e termociclador. Após a amplificação, foram adicionados, a cada amostra, $3 \mu \mathrm{L}$ de tampão de arrasto contendo $0,25 \%$ de azul de bromofenol e $60 \%$ de glicerol. Essas amostras foram aplicadas em gel de agarose $(1,2 \%)$, com brometo de etídio $(0,5 \mu \mathrm{g} / \mathrm{mL})$ e corridas em tampão TBE (Tris-borato-EDTA). Ao término das corridas, as imagens dos géis foram digitalizadas sob luz UV em um sistema de foiodocumentação Eagle Eye Ilâ. A amplificação por PCR, análise por RFLP e amplificação da região ITS (ITS/ ITS4) do rDNA foram realizadas conforme descrito por White et al. (1990). Após a amplificação das amostras de DNA, os produtos foram analisados por eletroforese, em gel de agarose $2 \%$ e/ou precipitados para análise por RFLP. O DNA foi analisado por eletroforese, em gel de agarose $0,8 \%$, numa cuba horizontal com uma corrente de 55 miliamperes e por 5 horas. Para isso, a agarose foi dissolvida em tampão TEB (Tris-borato 0,09 M e EDTA 0,002 M, pH 8,0) no forno microondas. Após o resfriamento, a uma temperatura de aproximadamente $45^{\circ} \mathrm{C}$, adicionou-se brometo de etídio, para uma concentração final de $0,2 \mu \mathrm{g} / \mathrm{mL}$. A solução foi vertida em uma placa de acrílico com um pente com dentes de $0,5 \mathrm{~cm}$ de largura e $0,15 \mathrm{~cm}$ de espessura, separados entre si por $0,3 \mathrm{~cm}$. Após a polimerização do gel, foram adicionados às amostras, $3 \mu \mathrm{L}$ de tampão (azul de bromofenol 0,25\% e glicerol $60 \%$ ) para que se pudesse avaliar a migração dos fragmentos de DNA durante a corrida. Os géis foram digitalizados em um sistema de fotodocumentação Eagle Eye llâ. Tanto os dados de RAPD quanto para os de PCR-RFLP, as fotografias foram analisadas codificando 1 para presença e 0 para ausência de bandas nas diferentes amostras, utilizando o coeficiente de Nei e Li (1979). O cálculo das distâncias genéticas foi feito a partir do programa genes descrito por Cruz (1997) e foram usadas para agrupar as cepas pelo método UPGMA ("unweighted pairgroup method using arithmetic means"), avaliados pelo programa STATISTICA 5.0 para Windows.

\section{Resultados e discussão}

Os resultados da amplificação estão nas Figuras 1 e 2. A amplificação resultou em um total de 107 fragmentos de DNA polimórficos, utilizando-se 11 oligonucleotídeos (Tabela 2). As distâncias genéticas variaram de 9 a $83 \%$, quando analisadas em conjunto, demonstrando grande diversidade genética nos isolados das três espécies utilizadas nesse ensaio. A análise do dendograma (Figura 3) construído a partir da matriz de distância genética, indicou não ser possível estabelecer uma correlação entre os cinco subgrupos de isolados, conside- 
rando o ano e o local da coleta. Por meio dessas análises, pôde-se diferenciar as cepas A51 (A.robusta) e A78 (A.conoides) das suas respectivas espécies. Além desses, a cepa A183 (A.oligospora) também se diferenciou de sua espécie, agrupando-se com isolados de A.robusta.

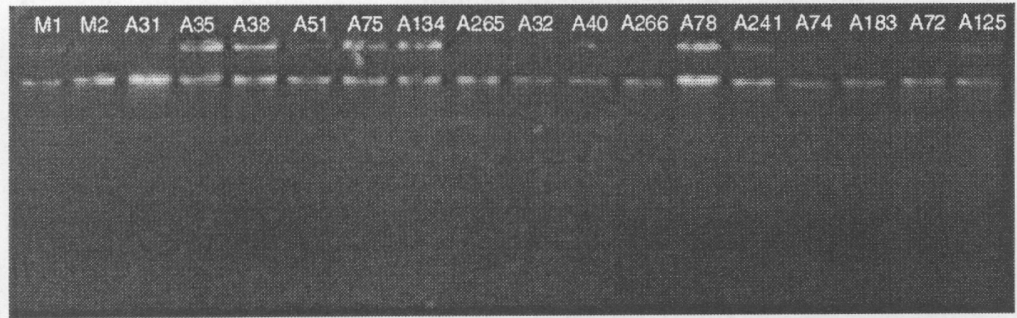

Figura 1- Eletroforese em gel de agarose $0,8 \%$ do DNA total das amostras das cepas fúngicas. As denominações das canaletas correspondem à identificação da Tabela 1. (M1 e M2) DNA de lambda, nas concentrações 20 e $50 \mathrm{ng} / \mu \mathrm{L}$, respectivamente
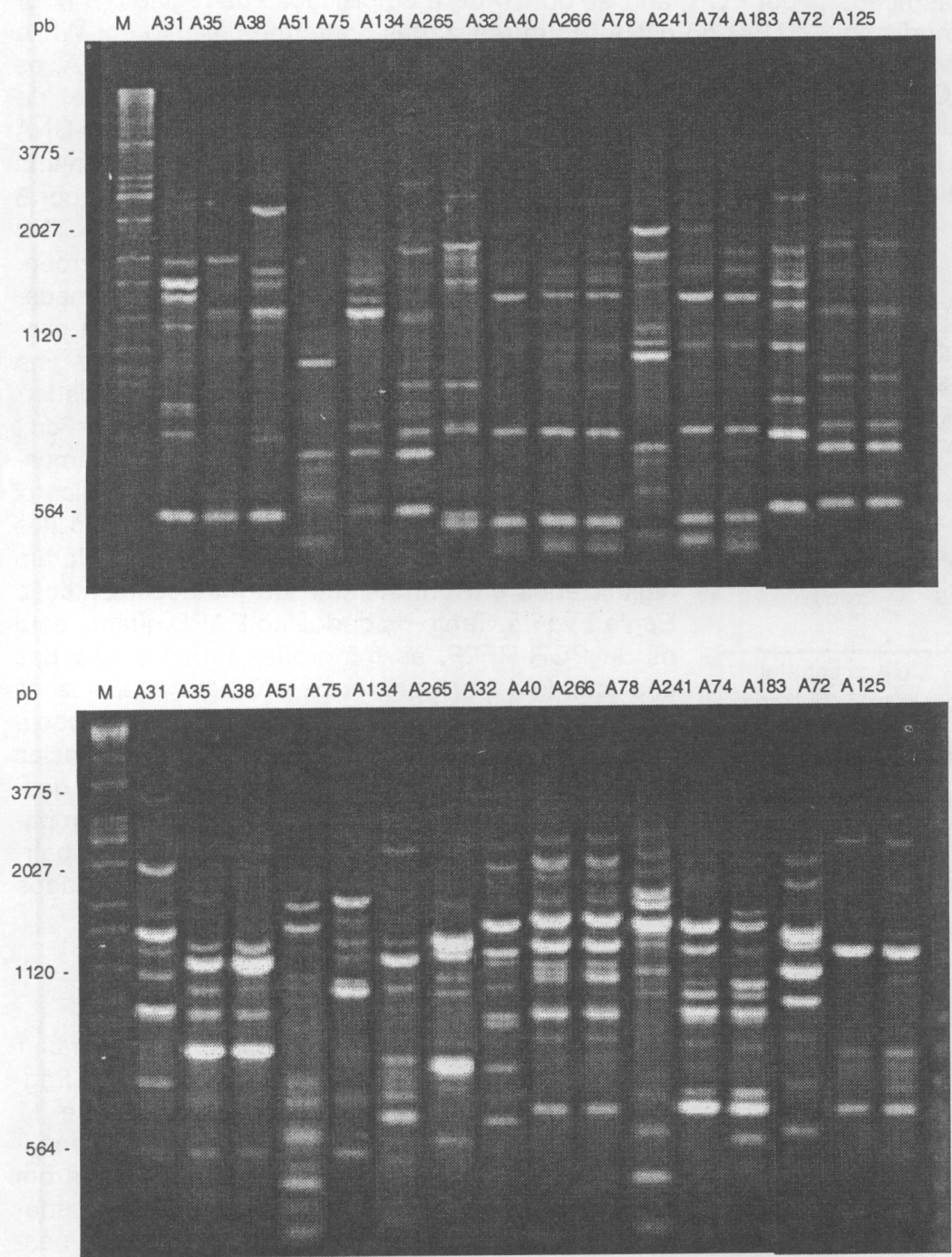

Figura 2 - Eletroforese em gel de agarose 1,2\% de DNA amplificado das cepas de $A$. robusta, $A$. conoides e A. oligospora utilizando oligonucleotídeos iniciadores OPEO4 (A) e OPF13 (B). As denominações das canaletas correspondem à identificação da Tabela 1. (M) DNA de lambda, hidrolisado com Hind III/Eco RI
Mahuku et al. (1998), usando marcadores RAPD, analisaram a diversidade genética de cepas do fungo Microdochium nivale e verificaram um alto grau de distância genética entre as populações. Por meio da análise do dendograma, observaram que das cepas da população, três eram geneticamente distantes das outras. Concluíram que essa divergência poderia ser um indicativo de especiação. Groth et al. (1995) sugeriram que a diversidade genética existente em uma população de Uromyces appendiculatus pode ser causada pela migração, seleção e recombinação sexual dos indivíduos. A existência e a freqüência da reprodução sexual nesse gênero não é conhecida na natureza, uma vez que este fungo está classificado como um Deuteromycetes.

Qualquer um dos polimorfismos observados durante a análise de RAPD pode ter ocorrido por eventos tais como substituição, inversão ou deleção de pares de base, no sítio de anelamento do oligonucleotídeo. O polimorfismo é detectado das cepas de diferentes localidades, independentemente da distância geográfica (Meijer et al., 1994). A técnica de RAPD mostrou-se confiável, rápida, reprodutível e de fácil execução. Seus marcadores demonstraram eficiência para detecção de polimorfismo genético interespecífico e intra-específico, quando os apreenderam entre as cepas de Arthrobotrys spp, durante a amplificação de fragmentos polimórficos de DNA.

A variação dentro do ITS do rDNA de seis cepas A.conoides e sete de A.robusta foi analisada por PCR seguida pela análise do polimorfismo de comprimento de restrição (RFLP). Essa região amplificada inclui o espaçador interno transcrito (ITS), que possui um baixo grau de conservação. O tamanho do produto da amplificação variou de 580 a 700pb aproximadamente, e em cada um deles foi amplificado apenas um fragmento de DNA (Figura 4). Houve polimorfismo de tamanho na região ITS do isolado $A 78$ da espécie $A$. conoides e da cepa $A 51$ de $A$. robusta dentro de suas respectivas espécies. Para determinação do polimorfismo de comprimento dos fragmentos de restrição, os produtos de amplificação da região ITS foram hidrolisados com as enzimas de restrição Cla I, Eco RI e Hinf I. A Figura 5 mostra o padrão de fragmentos de DNA obtidos com a enzima Hinf I. A hidrólise do DNA, com essas enzimas, resultou em fragmentos de tamanhos diferentes, indicando polimorfismo para todas as enzimas utilizadas (Tabela 3). O DNA total das cepas fúngicas produziram padrões idênticos de PCR-RFLP, quando se utilizaram diferentes enzimas de restrição, dentro de cada espécie.

O dendograma (Figura 6), construído a partir dos dados da matriz de distância genética para as espécies de $A$. conoides e $A$. robusta, da região ITS do rDNA, definiu a formação de três grupos. O primeiro grupo foi formado pelas cepas de $A$. conoides, com exceção do A 78; o segundo, formou-se pelas cepas de $A$. robusta, com exceção do A51 que juntamente com o A78 agruparam-se formando o terceiro grupo. Isto pode ter 
Tabela 2 - Relação dos oligonucleotídeos, das respectivas seqüências de bases e do número dos fragmentos polimórficos analisados

\begin{tabular}{ccc}
\hline Oligonucleotídeos & Seqüência $5^{\prime} \rightarrow 3^{\prime}$ & Fragmentos polimórficos \\
\hline OPE02 & GGTGCGGGAA & 13 \\
OPE04 & GTGACATGCC & 13 \\
OPE05 & TCAGGGAGGT & 11 \\
OPE06 & AAGACCCCTC & 10 \\
OPE09 & CTTCACCCGA & 10 \\
OPE10 & CACCAGGTGA & 8 \\
OPE13 & CCCGATTCGG & 11 \\
OPF08 & GGGATATCGG & 11 \\
OPF10 & GGAAGCTTGG & 11 \\
OPF13 & GGCTGCAGAA & 10 \\
OPF18 & TTCCCGGGTT & 7 \\
\hline
\end{tabular}

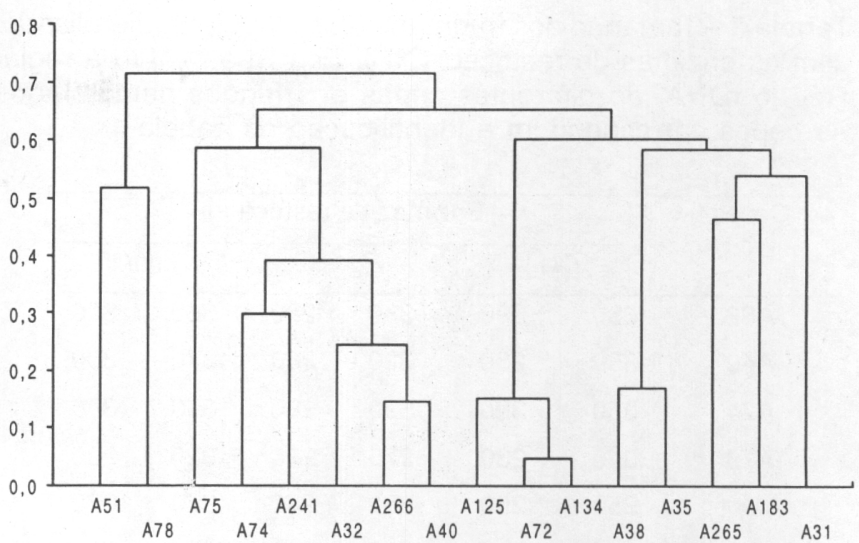

Figura 3 - Dendrograma construído pelo método UPGMA, com base nas distâncias genéticas das cepas de $A$. robusta, $A$. conoides e $A$. oligospora. As denominações A31 até A266 correspondem às identificações da Tabela 1

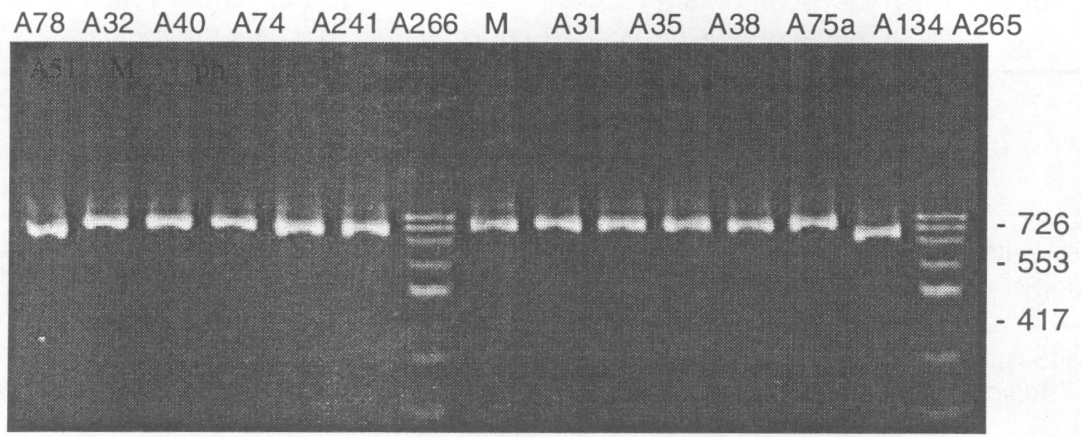

Figura 4 - Gel de eletroforese em agarose $2 \%$ da região ITS do rDNA de seis cepas de Arthrobotrys conoides, e das sete de A. robusta, amplificada por PCR. As denominações das canaletas correspondem às identificações da Tabela 1. (M) DNA de $\phi \times 174$ hidrolisado com Hinf I

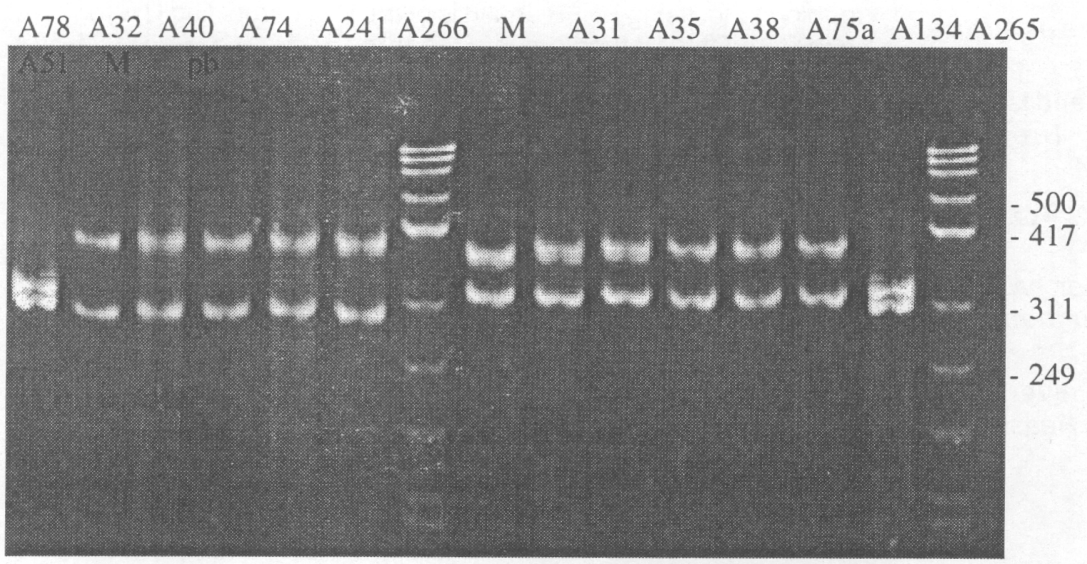

Figura 5 - Gel de eletroforese em agarose $2 \%$ da região ITS do rDNA de seis cepas de Arthrobotrys conoides, e das sete de A. robusta, amplificada por PCR e hidrolisada com a enzima de restrição Hinf I. As denominações das canaletas correspondem às identificações da Tabela 1. (M) DNA do fago $\phi X 174$, hidrolisado com Hinf I ocorrido por causa de um polimorfismo dentro de classificação das cepas A51 e A78, uma vez que estes não se agruparam às suas respectivas espécies. Pearson et al. (1996) estudaram a caracterização de seis cepas de Arthrobotrys oligospora. A identificação de cada um foi feita de acordo com a sua morfologia, usando marcadores em nível de DNA (PCR-RFLP de rDNA). Cinco cepas apresentaram um padrão de restrição idêntico. O sexto apresentou um padrão similar, mas não idêntico aos demais. Ahrén et al. (1998) fizeram análise filogenética com base nas seqüências do rDNA de 15 espécies de fungos nematófagos, e verificaram que o padrão filogenético não estava de acordo com a morfologia dos conídios. Dividiram, portanto, os resultados do agrupamento, em três linhas: espécies com anéis constritores, espécies não-parasitas e espécies com várias estruturas adesivas passíveis de infecção por nematóides.

Análises genéticas com marcadores RAPD permitem agrupar indivíduos que pertencem a uma mesma população e espécie. Nessa análise, foi possível agrupar com exceção de A51, A78 e A183, todas as cepas pertencentes a $A$. conoides, $A$. oligospora e A. robusta dentro de suas respectivas espécies. Já as análises por PCR-RFLP do rDNA, permitem uma análise interespecífica. Com essa análise houve agrupamento das cepas dentro de suas respectivas espécies e a exclusão de A51 e A78. 
Tabela 3 - Tamanho dos fragmentos de DNA (pb), hidrolisados com as enzimas de restrição $\mathrm{Cla}$ I, Eco RI e Hinf I da região ITS do rDNA, de diferentes cepas dos fungos nematófagos. As cepas correspondem à identificação da Tabela 1

\begin{tabular}{lllllll}
\hline Cepas & \multicolumn{6}{c}{ Enzimas de restrição } \\
\cline { 2 - 7 } Clal & \multicolumn{2}{c}{ Eco RI } & \multicolumn{2}{c}{ Hinf I } \\
\hline A32 & 350 & 290 & 330 & 280 & 360 & 300 \\
A40 & 350 & 290 & 320 & 280 & 370 & 300 \\
A74 & 350 & 290 & 320 & 280 & 370 & 300 \\
A78 & 340 & 230 & 270 & 270 & 320 & 290 \\
A241 & 350 & 290 & 330 & 280 & 370 & 320 \\
A266 & 350 & 290 & 330 & 280 & 370 & 320 \\
A31 & 350 & 290 & 340 & 300 & 370 & 320 \\
A35 & 350 & 290 & 350 & 300 & 380 & 320 \\
A38 & 350 & 290 & 340 & 300 & 390 & 320 \\
A51 & 320 & 220 & 280 & 280 & 320 & 300 \\
A75 & 350 & 290 & 340 & 300 & 390 & 320 \\
A134 & 350 & 290 & 340 & 300 & 390 & 320 \\
A265 & 350 & 290 & 360 & 320 & 390 & 320 \\
\hline
\end{tabular}

\section{Referências}

AHRÉN, D., URSING, B.M., TUNLID, A. Phylogeny of nematode-trapping fungi based on $18 \mathrm{~S}$ rDNA sequences. FEMS Microbiology Letters, v.158, p.179-184, 1998.

ARAÚJO, J.V. Controle de nematóides parasitos de bovinos por fungos nematófagos. Uma nova alternativa?. Cadernos Técnicos de Veterinária e Zootecnia da UFMG, v. 30, p. 75-88, 1999.

ARAÚJO, J.V., JUNGHANS, T.G., ALFENAS, A.C. Isoenzyme analysis of Arthrobotrys, a nematode-trapping fungus. Brazilian Journal of Medical and Biological Research,v. 30, p. 1149-1152, 1997.

COOKE, R.C., GODFREY, B.E.S. A key of nematode-destroying fungi. Transation British Mycological Society, v. 47, p. 61-74, 1964.

CRUZ, C.D. (Ed.). Aplicativo computacional em genética e estatística. Viçosa: Editora UFV, 1997.

GROTH, J.V., MCCAIN,J.W., ROELFS, A.P. Virulence and isozyme diversity of sexual versus asexual colletions os Uromyces appendiculatus. Heredity, v. 75, p. 234-242, 1995.

HAARD, K. Taxonomic studies on the genus Arthrobotrys corda. Mycologia, v. 60, p. 1140-1159, 1968.

KADO, C.I., HESKET, M.G. Selective media for isolation of Agrobacterium, Corynebacterium, Erwinia, Pseudomonas and Xanthomonas. Phytopathology, v. 60, p. 969-976, 1970.

MAHUKU, G.S., HSIANG, T., YANG, L. Genetic diversity of Microdochium nivale isolate from turfgrass. Micological Reaserch, $v$. 102, p. 559-567, 1998.

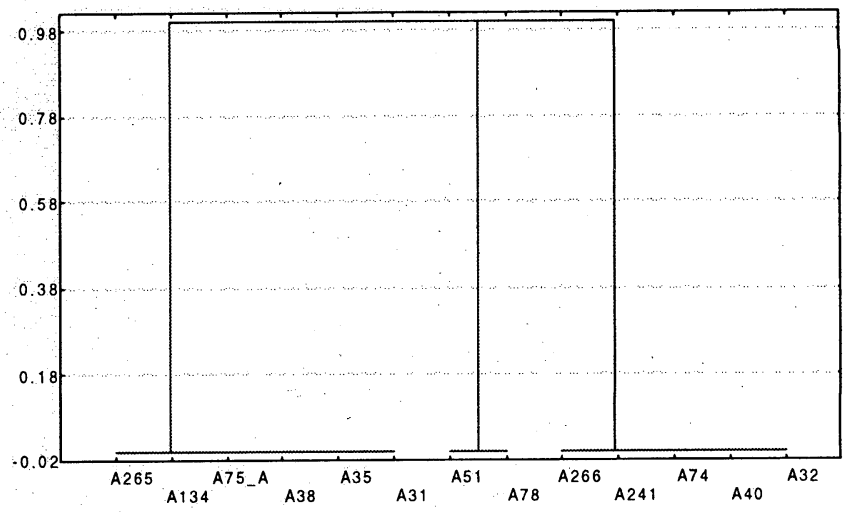

Figura 6 - Dendrograma da região ITS de cepas de $A$. conoides e $A$. robusta elaborado pelo método UPGMA. As denominações A31 até A266 correspondem às identificações da Tabela 1

\section{Conclusões}

Sugerimos, então, que, por apresentarem diferentes padrões de polimorfismo, quando comparados com suas respectivas espécies, as cepas A51 ( $A$. robusta), A78 ( $A$. conoides) e A183 (A. oligospora), devam ter suas classificações revistas.

MEIJER. G., MEGNEGNEAU, B. LINDERS, E.G.A. Variability form isozyme, vegetative compatibility and RAPD markers in natural populations of Phomopsis subordinaria.. Micological Reaserch, v. 98, p. 267-276, 1994.

NEI, M., LI, W.K. Mathematical model for studying genetic variation in terms of restriction endonucleases. Proceedings of National Academy of Sciences of the USA, v. 76, p. 5269-5273, 1979.

NORDBRING-HERTZ, B. Nematophagous fungi: strategies for nematode exploitation and for survival. Microbiological Sciences, v. 5, p.108$116,1988$.

PERSSON, Y., ERLAND, S., JANSSON, H. Identification of nematodetrapping fungi using RFLP analysis of the PCR-amplified ITS region of ribosomal DNA. Mycological Research, v. 100, n. 5, p. 531-534, 1996.

SPECH,C.A. DIRUSSO,C.C., NOUTNY,C.P., ULLRICH, R.C. A method for extrating high molecular weight deoxyribonucleic acid from fungi. Analytical Biochemistry, v. 119, p. 158-163, 1982.

VANOORSCHOT, C.A.N. Taxonomy of the Dactylariacomples. A review of Arthrobotrys and allied genera. Studies in Mycologia, v. 26, p. 6196,1985.

WHITE, T.J., BRUNS, T., LEE, S. Amplification and direct sequencing of fungal ribosomal RNA genes for phylogenetics. In: INNIS M.A,; GELFAUD, D.H.,; SNINSKY, J.J. WHITE, T.J. (Eds.) PCR protocols: a guide to methods and applications. San Diego: Academic Press, 1990, p. 315-322. 